\title{
Norcantharidin Enhances High Concentrations of Fetal Bovine Serum-Induced Apoptosis in Human Mesangial Cells by Regulating the Mitogen-Activated Protein Kinase Signaling Pathway
}

\author{
Kun Yea Qiao-Yu Wei ${ }^{a}$ Teng-Xiang Long ${ }^{b}$ Hong-Guang $\mathrm{He}^{a}$ \\ Yun-Feng Huang ${ }^{a}$ Li-Jia Xiong ${ }^{a}$ Jiao Lan ${ }^{a}$ Yi-Yun Huang ${ }^{a}$ \\ Zhi-Feng Gong ${ }^{\text {a }}$ Xiao-Mei Peng ${ }^{a}$ Qiu-Xia Wu ${ }^{a}$ \\ ${ }^{a}$ Department of Nephrology, The People's Hospital of Guangxi Zhuang Autonomous \\ Region, Qingxiu, China; ${ }^{b}$ Department of Sci-Tech Novelty Retrieval, Guangxi Medical \\ Information Institute, Qingxiu, China
}

\section{Keywords}

Norcantharidin · Human mesangial cells · Apoptosis - Mitogen-activated protein kinase pathway

\begin{abstract}
Aim: This study aimed to investigate the effect of norcantharidin (NCTD) on human mesangial cells (HMCs) apoptosis in vitro and further examine its molecular mechanism. Methods: HMCs were divided into 5 groups: control group, 25\% fetal bovine serum (FBS)-treated group, and NCTD groups (NCTD [2.5, 5 and $10 \mu \mathrm{g} / \mathrm{mL}]+25 \%$ FBS, respectively). Cell proliferation was determined by MTT assay, while apoptosis was evaluated by Hoechest 33258 staining, the level of cytochrome c, immunohistochemistry, and apoptotic-related proteins/gene expression. Results: Cell viability was inhibited in NCTD-treated HMCs in a dose-dependent manner. The number of apoptotic cells and the content of cytochrome $c$ were significantly increased by NCTD treatment but that of mitochondrial membrane was decreased. Moreover, the expression of bcl-2 and caspase- 3 was prompted by NCTD, but the expression of bax, MMP-2, and MMP-9 in 25\% FBS-treated HMCs was inhibited. In addition, NCTD markedly unregulated the expression of apoptosis-related gene/protein, including $\mathrm{p}$-Erk1/2, phosphorylated-Jun N-terminal kinase (JNK), p-p38, and p53. Conclusion: NCTD enhances 25\% FBS-treated HMC apoptosis in vitro, and this effect may be attributed to the modulation of the ERK, JNK, and p38 mitogen-activated protein kinase signaling pathways.




\section{Kidney \\ Blood Pressure \\ Research}

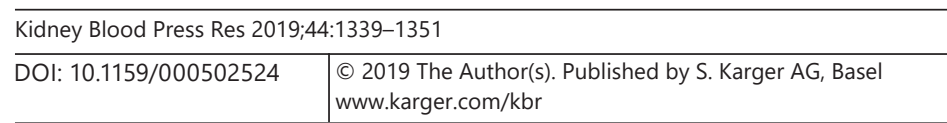

Ye et al.: NCTD Enhances High Concentrations of FBS-Induced Apoptosis in HMCs by Regulating the MAPK Signaling Pathway

\section{Introduction}

Glomerulonephritis is an important cause of morbidity and mortality in patients of all ages worldwide [1, 2]. Mesangial proliferative glomerulonephritis (MsPGN) is the common pathological type of glomerulonephritis, which may contribute to poor patient outcome and high risk of end-stage renal failure [3]. To date, there is no optimal treatment for MsPGN [4]. Hence, it is urgent to find novel therapies to prevent this disease. The imbalance between mesangial cell proliferation and apoptosis is a critical pathological cause for MsPGN. Accumulating evidence has shown that mitogen-activated protein kinase (MAPK) signaling pathways, which consist of at least 3 distinct subfamilies (extracellular regulated protein kinases [ERK], Jun N-terminal kinase [JNK], and p38 MAPK pathways), are involved in the initiation and progression of MsPGN [5-7]. JNK signaling inhibits cell proliferation and promotes apoptosis $[8,9]$, while P38 signaling inhibits cell proliferation but promotes cell migration [10]. Phosphorylated JNK (p-JNK) makes cell cycle arrest and apoptosis by activating p53, caspase-9, and caspase-3 [11]. As downstreams of p38 MAPK signaling, MMP-2, and MMP-9 are key enzymes involved in cell proliferation and migration [12]. ERK is primarily associated with cell proliferation, migration, and senescence $[13,14]$. Thus, the cell proliferation could be inhibited by inducing the cell apoptosis [15].

Norcantharidin (NCTD) is a synthetic demethylated analog of cantharidin, which is a traditional Chinese herb. NCTD has been used as an anticancer drug, such as liver cancer [16, 17], gastric cancer [18], renal cancer [19], colon cancer [20], prostate cancer [21], and so on. It has been reported that NCTD can enhance oxidative stress, promote apoptosis, and modulate the cell cycle [22-24]. NCTD exhibits a protective effect on renal tubule interstitial fibrosis by modulating the TGF- $\beta 1$-Smad signal cascade, inhibiting NF- $\kappa \mathrm{B}$, and decreasing PP2Ac expression, which is a profibrotic factor [25-27]. Interestingly, it has been revealed that NCTD possesses antiangiogenesis effects on human umbilical endothelial cells via downregulating MAPK signaling [28]. Recently, it was found that NCTD was effective in inhibiting human mesangial cell (HMC) proliferation and apoptosis [29]. In addition, NCTD appeared to induce little side effects and lesser metabolic distribution in vitro [30].

In the present study, the effect of NCTD on MsPGN proliferation model, which was induced by high concentration fetal bovine serum (FBS), was investigated, and the apoptosis level and underlying MAPKsignaling pathway were explored. The present study expands our knowledge of therapeutic potentials of NCTD for the treatment of glomerulonephritis, especially MsPGN.

\section{Materials and Methods}

\section{Materials}

NCTD was purchased from Sichuan Sunnyhope Pharmaceutical Co. Ltd. (Sichuan, China). FBS and RPMI-1640 were purchased from Gibco (Grand Island, NY, USA). Dimethyl sulfoxide and MTT were purchased from Beijing Solarbio Science and Technology Co. Ltd. (Beijing, China). The Hoechst 33258 fluorescent dye kit and mitochondrial membrane potential assay kit with JC-1 were purchased from Beyotime Institute of Biotechnology (Shanghai, China). Human Cytochrome C enzyme-linked immunosorbent assay Kit was purchased from Cuasbio Biotech Co. Ltd. (Wuhan, China).

\section{Cell Culture}

HMCs were provided by Professor Wen-ge Li of China-Japan Friendship Hospital. These HMCs were cultured in RPMI-1640 supplemented with $10 \% \mathrm{FBS}, 100 \mathrm{U} / \mathrm{mL}$ of penicillin, and $100 \mathrm{mg} / \mathrm{mL}$ of streptomycin at $37^{\circ} \mathrm{C}$ in a humidified atmosphere containing $5 \% \mathrm{CO}_{2}$. 


\section{Kidney \\ Blood Pressure \\ Research}

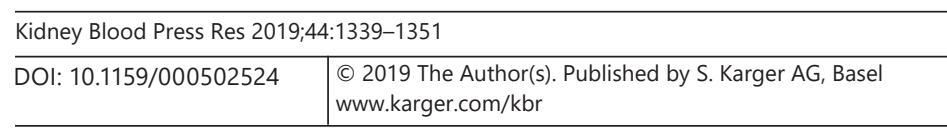

Ye et al.: NCTD Enhances High Concentrations of FBS-Induced Apoptosis in HMCs by Regulating the MAPK Signaling Pathway

\section{Proliferative Assay and Half Maximal Inhibitory Concentration Determination}

The proliferation inhibition potential of NCTD was determined in HMCs using the MTT method. Briefly, cells were seeded in a 96-well plate at a density of $5 \times 10^{3}$ cells/well and were incubated with $25 \%$ FBS for $48 \mathrm{~h}$. Then, these were treated with NCTD at final concentrations of 2.5, 5.0,10.0, or $20.0 \mu \mathrm{g} / \mathrm{mL}$ for $12 \mathrm{~h}$. Untreated cells served as the control group. The viability of cells was assessed using the MTT kit (Amresco, USA), according to manufacturer's protocol. The absorbance of the mixture was measured at $490 \mathrm{~nm}$ using a GF-M3000 microplate reader (Shandong Caihong, China). The results were calculated as previously described [31]. The inhibitory concentration values were calculated using nonlinear regression analysis.

\section{Nuclear Morphology Observation by Hoechst 33258 Staining Assay}

In order to investigate the cell apoptosis, nuclear morphological analysis was performed by Hoechest 33258 staining. HMCs of $1 \times 10^{6}$ cells per well were plated in a 6-well plate. After the fresh medium was changed with $25 \%$ FBS after $48 \mathrm{~h}$, different concentrations of NCTD $(2.5,5$, and $10 \mu \mathrm{g} / \mathrm{mL})$ were added into these HMCs. Untreated cells served as the control group. About $12 \mathrm{~h}$ later, each well was fixed in 4\% paraformaldehyde for $15 \mathrm{~min}$ at room temperature. Subsequently, these cells were gently washed 3 times with PBS, followed by incubation with $1 \mathrm{~mL}(5 \mu \mathrm{g} / \mathrm{mL})$ of Hoechst 33258 solution per well at $37^{\circ} \mathrm{C}$ for $10 \mathrm{~min}$ in the dark. At the end of the incubation, cells were washed with PBS and mounted by antifade mounting medium. Then, the images were captured and observed using a fluorescence microscope (Olympus IX71, Tokyo, Japan) with an excitation wavelength of 330-380 nm. Strong fluorescence was observed in the nuclei of apoptotic cells, while weak fluorescence was observed in nonapoptotic cells. The quantification of apoptotic cells was performed via taking the images in random fields and counting at least 200 cells in 4 random fields in each well.

\section{Determination of Mitochondria Membrane Potential $(\Delta \psi m)$}

HMCs at $1 \times 10^{6}$ cells were cultured in 6-well plates in $2.5 \mathrm{~mL}$ of RPMI-1640 medium for $24 \mathrm{~h}$. The medium was changed with fresh medium with RPMI-1640 plus 25\% FBS after $48 \mathrm{~h}$. When the cell fusion rate reached approximately $80 \%$, the supernatant was discarded, 2 mL of FBS-free RPMI-1640 medium was added to each well, and these cells were cultured for $24 \mathrm{~h}$. Next, cells were further treated with NCTD $(2.5,5.0$, and $10.0 \mu \mathrm{g} / \mathrm{mL})$ for $12 \mathrm{~h}$. Then these cells were stained with mitochondrial membrane potential dye. Cells were incubated with $1 \mathrm{~mL}$ of working solution of JC-1 fluorescent dye for $20 \mathrm{~min}$ in the dark at $37^{\circ} \mathrm{C}$. Then, cells were gently washed twice with JC- 1 dyeing buffer. The mitochondrial membrane potential $(\Delta \psi \mathrm{m})$ was imaged using a fluorescence microscope at $550 \mathrm{~nm}$ excitation and 570 $\mathrm{nm}$ emission for JC-1.

\section{Determination of Cytochrome c Release in the Cytoplasm}

HMCs were seeded in a white-walled 96-well plate and treated with different concentrations $(2.5,5.0$, and $10.0 \mu \mathrm{g} / \mathrm{mL})$ of NCTD for $12 \mathrm{~h}$. Then, cytochrome c activity was determined using the enzyme-linked immunosorbent assay kit, according to manufacturer's protocol. Briefly, the treated cells were added with biotin-labeled antibody and incubated at $37^{\circ} \mathrm{C}$ for $1 \mathrm{~h}$. After washing working fluid was washed 3 washes, the wells were incubated with horseradish peroxidase-conjugated avidin at $37^{\circ} \mathrm{C}$ for $1 \mathrm{~h}$. Then, the samples were measured using a SpectraMax Plus384 microplate reader (Molecular Devices, USA). The progress of the reaction was monitored by measuring absorbance at $450 \mathrm{~nm}$. The results were expressed in $\mathrm{ng} / \mathrm{mL}$. 


\section{Kidney \\ Blood Pressure \\ Research}

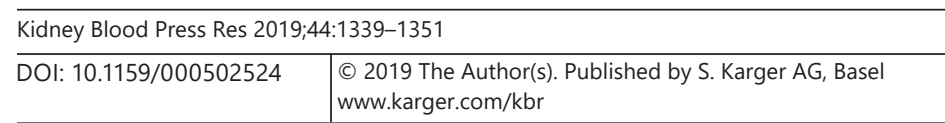

Ye et al.: NCTD Enhances High Concentrations of FBS-Induced Apoptosis in HMCs by Regulating the MAPK Signaling Pathway

Immunohistochemical Examination of Bax, bcl-2, Caspase-3, MMP-2, and MMP-9

HMCs were seeded in a 6-well plate and treated with different concentrations $(2.5,5.0$, and $10.0 \mu \mathrm{g} / \mathrm{mL}$ ) of NCTD for $12 \mathrm{~h}$. According to the immunohistochemistry staining method previously described [32], cells were fixed, permeabilized, and stained with the corresponding primary antibody: bax (Abcam, 1:1,000), bcl-2 (Abcam, 1:1,000), caspase-3 (Abcam, 1:1,000), MMP-2 (Cell Signaling, 1:1,000), and MMP-9 (Cell Signaling, 1:1,000). Images were taken using a Leica DM6000 microscope with a magnification of $\times 200$ (Olympus, Germany), and these were analyzed using ImagePro-Plus software. A cytoplasm stained brown was considered a standard for positive cells.

Detection of Erk1/2, Phospho (p)-Erk1/2, JNK, p-JNK, p38, p-p38, and p53 Protein Expression by Western Blot

HMCs were treated with various concentrations $(2.5,5.0$, and $10.0 \mu \mathrm{g} / \mathrm{mL})$ of NCTD for $12 \mathrm{~h}$. Protein extraction and western blot were performed, as previously described [33]. Briefly, the proteins were detected by incubating with primary antibodies (Erk1/2, p-Erk1/2, JNK, p-JNK, p38, p-p38, and p53 [all were purchased from Cell Signaling Technology, USA]) overnight at $4{ }^{\circ} \mathrm{C}$. After hybridization with horseradish peroxidase-conjugated secondary antibody, the protein bands were detected using Odyssey V 3.0 software. GAPDH was the protein loading control.

\section{Analysis of p53 mRNA by Real-Time Polymerase Chain Reaction}

HMCs were seeded in a 6-well plate at a density of 30,000 cells/well and treated with various concentrations $(2.5,5.0$, and $10.0 \mu \mathrm{g} / \mathrm{mL})$ of NCTD for $12 \mathrm{~h}$. The total RNA was extracted from cells using TRIzol reagent (Ambion, USA) and quantified by a spectrophotometer (Thermo Scientific, USA). Reverse transcription was carried out in $20 \mu \mathrm{L}$ of reaction mixture containing $1 \mu \mathrm{g}$ of total RNA. A reverse transcriptase (Takara) kit was used to synthesize the cDNA by incubating at $25^{\circ} \mathrm{C}$ for $10 \mathrm{~min}$, and subsequently at $50^{\circ} \mathrm{C}$ for $60 \mathrm{~min}$. Then, DNA amplification was performed using the cDNA template and primers (Invitrogen, USA) with the 7500 real-time polymerase chain reaction system (Applied Biosystems, USA). The sequences of the primers used in the present study were as follows: P53 (forward primer: 5'-GAACAGCTTTGAGGTGCGTG-3', reverse primer: 5'-CTTCTTTGGCTGGGGAGAGG-3') and GAPDH (forward primer: 5'-TTCACCACCATGGAGAAGGC-3', reverse primer: $5^{\prime}$-AGAGGGGGCAGAGATGATGA-3'). The final results were described with the relative values $\left(2^{-} \Delta \Delta^{\mathrm{Ct}}\right)[34]$.

\section{Statistical Analysis}

Statistical analysis was performed by SPSS version 17.0, and all data were presented as mean \pm SD. Differences between 2 groups were compared using Student $t$ test when these had a normal distribution. One-way analysis of variance was used to compare data among groups when these had normal distribution and homogeneous variances. A $p$ value of $<0.05$ was considered statistically significant.

\section{Results}

\section{NCTD Inhibits the Viability of HMCs}

MTT assay was used to evaluate the viability of HMCs. Following NCTD treatment on HMCs, it was found that cells grew slowly, distorted, round in , and detached from the bottom of the plate. Furthermore, the number of detached cells increased as the increasing drug concentration. As shown in Figure 1, cell viability was significantly higher in cells only treated 
Ye et al.: NCTD Enhances High Concentrations of FBS-Induced Apoptosis in HMCs by Regulating the MAPK Signaling Pathway

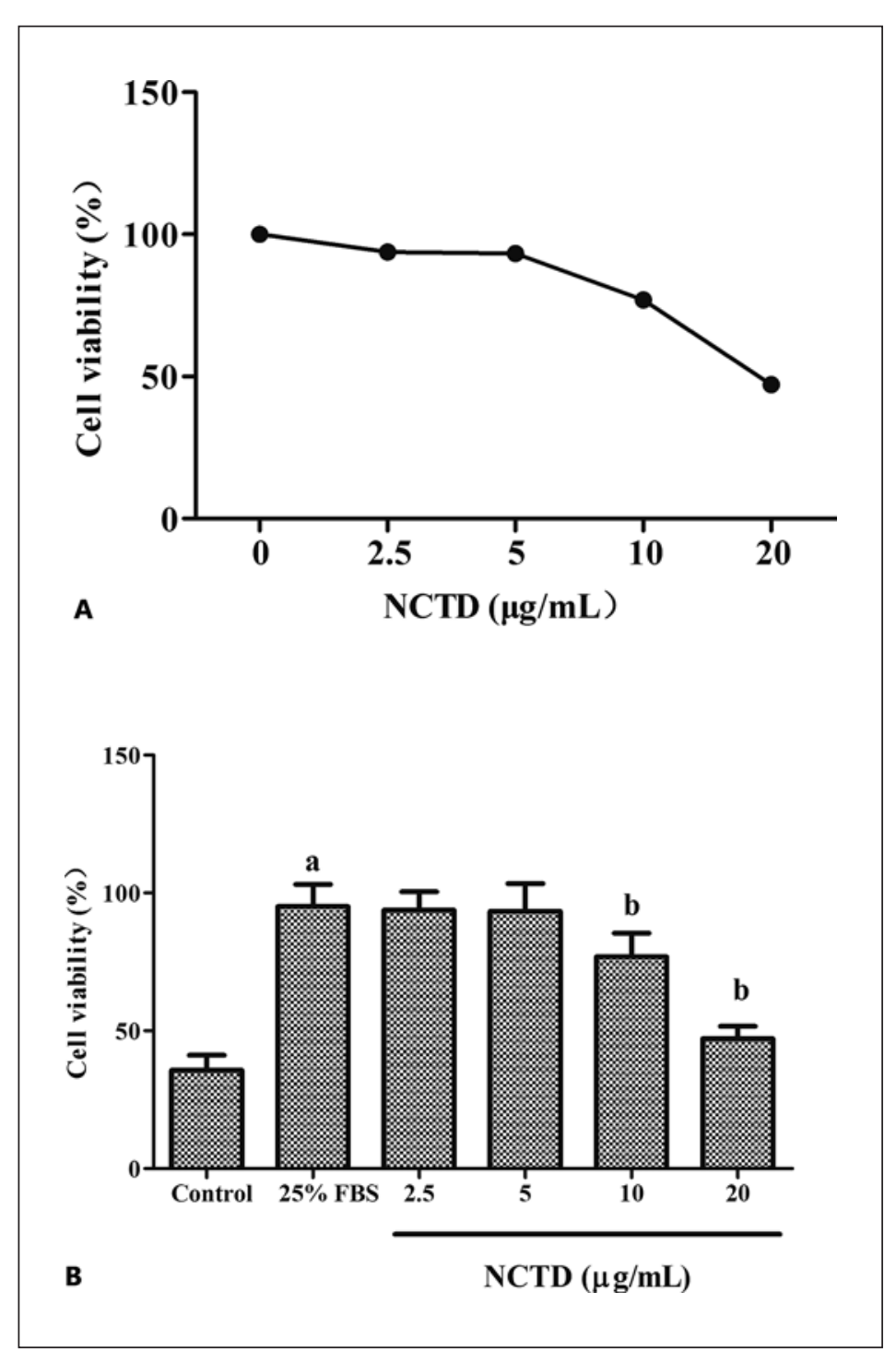

Fig. 1. Cell viability. A The cytotoxicity of NCTD on 25\% FBS-induced HMCs. B NCTD decreased cell viability in 25\% FBS-induced HMCs. Values are presented as the mean $\pm \operatorname{SD}(n=3) .{ }^{\mathrm{a}} p<0.05$, compared with control group, b $p<0.05$, compared with $25 \%$ FBS group. NCTD, norcantharidin; FBS, fetal bovine serum.

with $25 \%$ FBS, which was inhibited by NCTD $(10$ and $20 \mu \mathrm{g} / \mathrm{mL} ; p<0.05)$ in a dose-dependent manner. The inhibitory concentration value of NCTD in HMCs was $19.75 \mu \mathrm{g} / \mathrm{mL}$, which was calculated by the SPSS software.

\section{NCTD Causes Nuclear Condensation and Cell Apoptosis}

The bodies of apoptotic cells shrank in volume and became round. The concentration of the cell nucleus was observed, and the cell nucleus became white after being stained by Hoechst 33258 under a fluorescent microscope. Untreated HMCs, which displayed normal chromatin patterns and cell size, were stained with Light blue florescence (Fig. 2). After $12 \mathrm{~h}$ of treatment with NCTD, these cells exhibited chromatin condensation, cellular shrinkage, apoptotic bodies, and cytoplasmic condensation and were stained with higher blue florescence. The number of apoptotic cells underwent similar change in cells subjected to $25 \% \mathrm{FBS}$, when compared to the normal control group (Fig. 2; $p>0.05$ ). However, compared with the model group, the number of apoptotic cells increased after NCTD treatment $(2.5,5.0$, and 10.0 $\mu \mathrm{g} / \mathrm{mL} ; p<0.05)$. 
Kidney

Blood Pressure

Research
Kidney Blood Press Res 2019;44:1339-1351 DOI: $10.1159 / 000502524$

(c) 2019 The www.karger.com/kb

Ye et al.: NCTD Enhances High Concentrations of FBS-Induced Apoptosis in HMCs by Regulating the MAPK Signaling Pathway

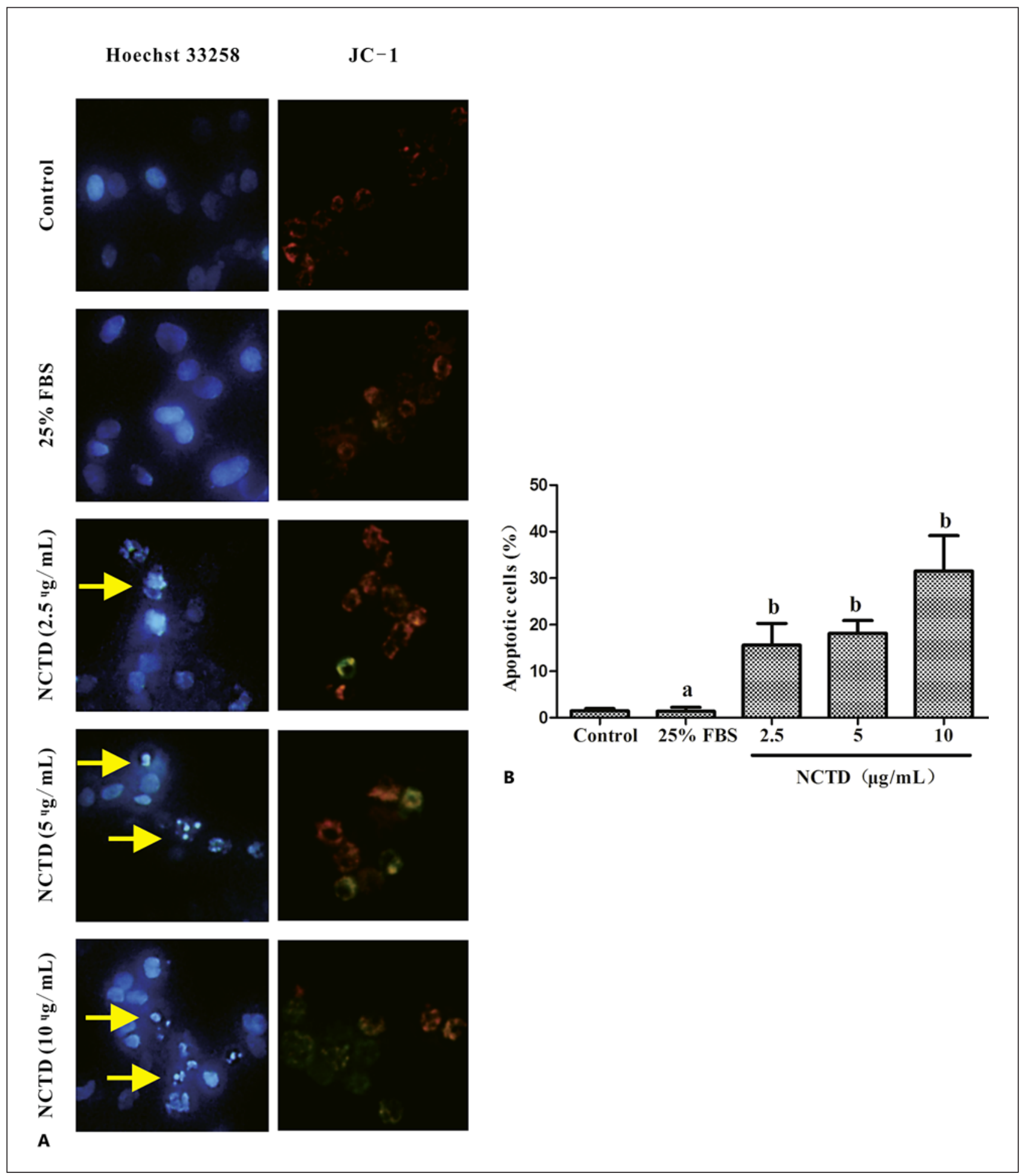

Fig. 2. Multiplex morphological analysis of the cytotoxicity of NCTD on 25\% FBS-induced HMCs. A Representative cell images in Hoechst 33258 staining and JC-1 determination of mitochondrial membrane potential. Te arrows point to apoptotic cells. B Changes in apoptotic cells. Values are presented as the mean \pm SD $(n=$ 3). ${ }^{\mathrm{a}} p<0.05$, compared with control group, ${ }^{\mathrm{b}} p<0.05$, compared with $25 \%$ FBS group. FBS, fetal bovine serum; NCTD, norcantharidin. 
Fig. 3. NCTD-enhanced cytochrome c release on 25\% FBS-induced HMCs. Values are presented as the mean $\pm \operatorname{SD}(n=3) .{ }^{\mathrm{a}} p<$ 0.05 , compared with control group, ${ }^{\mathrm{b}} p<0.05$, compared with $25 \%$ FBS group. FBS, fetal bovine serum; NCTD, norcantharidin.

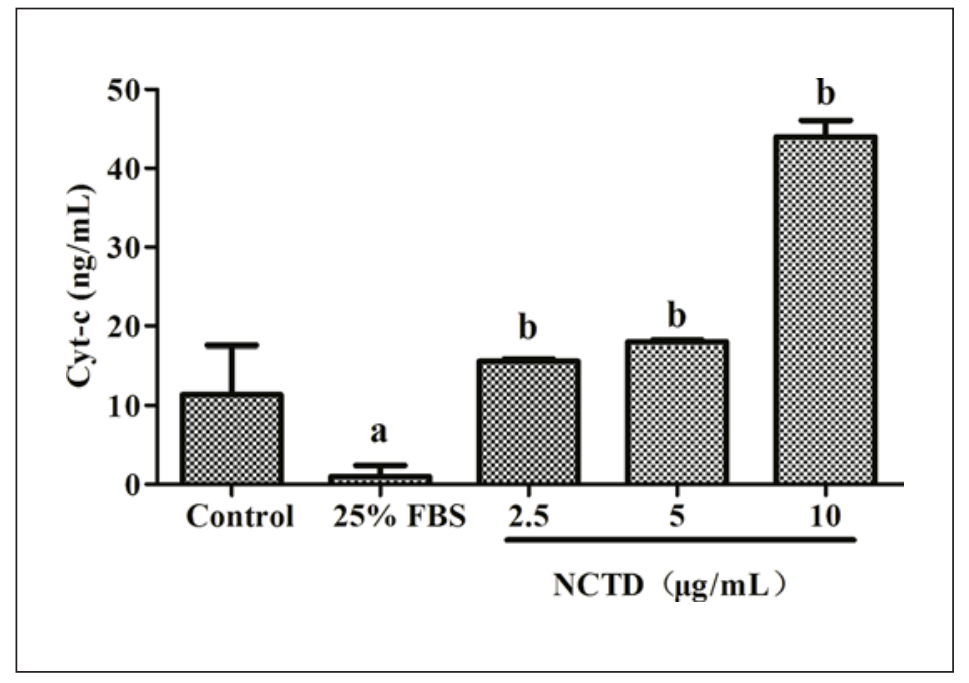

NCTD Causes the Disruption of $\triangle \psi m$ in HMCs

The representative microphotographs of the fluorescence stain were presented in Figure 2. Following the treatment with NCTD $(2.5,5.0$, and $10.0 \mu \mathrm{g} / \mathrm{mL})$, the red light was significantly decreased, which was accompanied by increasing green light in HMCs.

\section{Cytochrome c Release}

As shown in Figure 3, NCTD treatment could trigger cytochrome c release from the mitochondria after $12 \mathrm{~h}$ of intervention. The cytochrome c level in HMCs decreased in the model group, when compared to the control group $(p<0.05)$. Interestingly, these alternations reversed following NCTD treatment $(2.5,5.0$, and $10.0 \mu \mathrm{g} / \mathrm{mL} ; p<0.05)$.

\section{NCTD Induced the Apoptosis of HMCs}

The immunohistochemical changes of HMCs were presented in Figure 4. A decline in the number of bcl-2, MMP-2, and MMP-9 positive cells and an increase in the number of bax and caspase-3 positive cells were observed in the $25 \%$ FBS group, when compared to the control group. The treatment with NCTD $(5.0$ and $10.0 \mu \mathrm{g} / \mathrm{mL})$ produced a significant reverse on these changes.

\section{Effect of NCTD on Apoptotic-Related Protein Expression}

As shown in Figure 5, in the model group, the phosphorylation level of Erk1/2, JNK and p38 significantly decreased by $20.0,36.4$, and $23.8 \%$, respectively, when compared to the control group. By treatment with NCTD $(2.5,5.0$, and $10.0 \mu \mathrm{g} / \mathrm{mL})$, the expression of p-Erk1/2, p-JNK, and p-p38 increased, when compared with the model group. Meanwhile, the protein expression of p53 was significantly lower in the model group, when compared with the control group, and the effect of that was significantly ameliorated by NCTD treatment (2.5, 5.0 , and $10.0 \mu \mathrm{g} / \mathrm{mL}$ ).

\section{Effect of NCTD on p53 mRNA Expression}

In the present study, the effect of NCTD on p53 mRNA level in HMCs was determined by real-time-polymerase chain reaction. As shown in Figure 6, compared to the control group, the p53 mRNA level in the model group was significantly reduced, but markedly increased after NCTD treatment at various concentrations $(2.5,5.0$, and $10.0 \mu \mathrm{g} / \mathrm{mL})$. 
Kidney

Blood Pressure

Research

\begin{tabular}{l|l}
\hline Kidney Blood Press Res 2019:44:1339-1351 \\
\hline DOI: 10.1159/000502524 & $\begin{array}{l}\text { @ 2019 The Author(s). Published by S. Karger AG, Basel } \\
\text { www.karger.com/kbr }\end{array}$ \\
\hline
\end{tabular}

Ye et al.: NCTD Enhances High Concentrations of FBS-Induced Apoptosis in HMCs by Regulating the MAPK Signaling Pathway

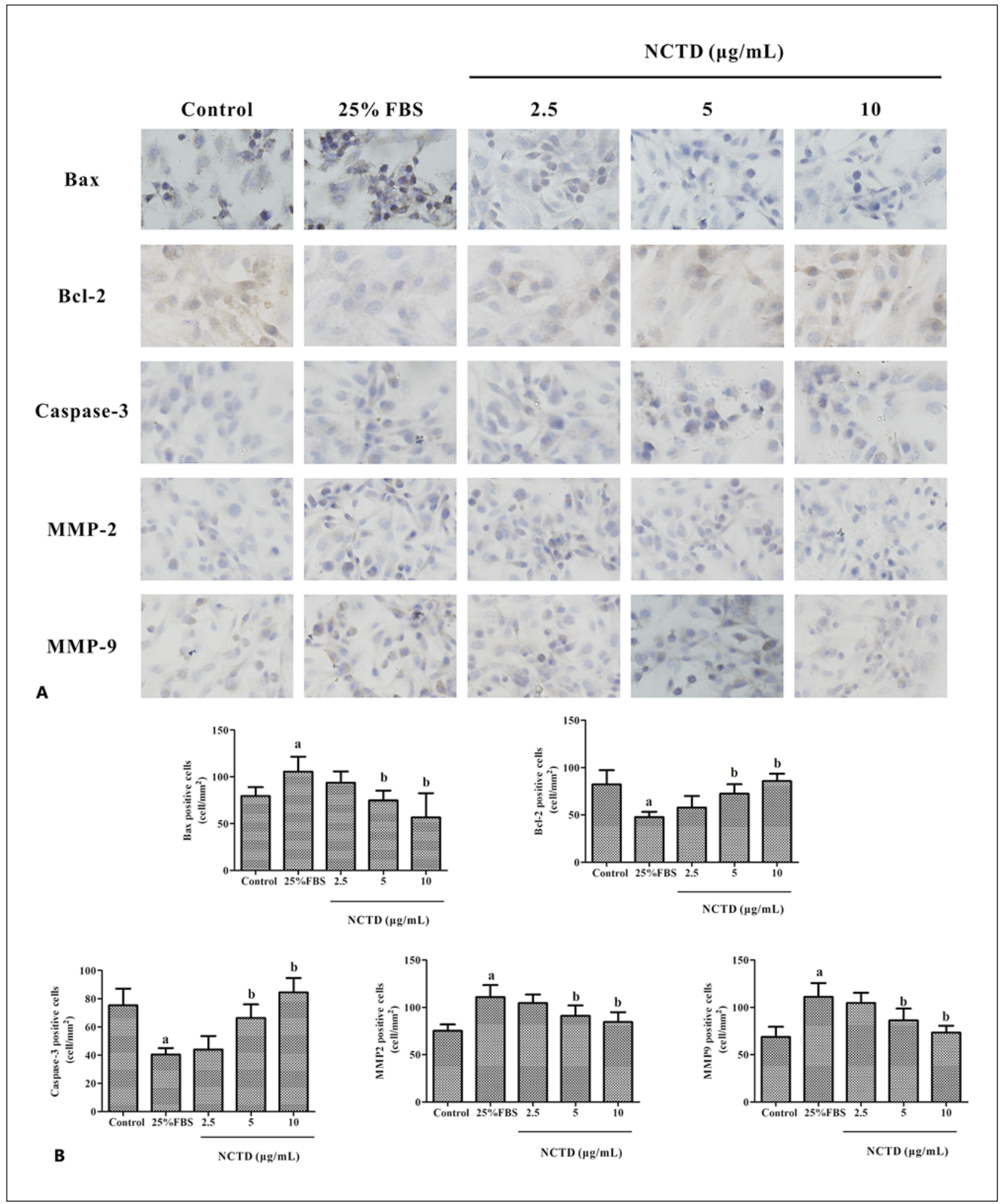

Fig. 4. Immunohistochemical changes. HMCs were stained with DAB and antibody against bax, bcl-2, caspase-3, MMP-2, and MMP-9. A Representative images displaying the number of positive cells. B Calculation of the number of positive cells (cells $/ \mathrm{mm}^{2}$ ). Each column represents the mean $\pm \operatorname{SD}(n=3)$. Scale bar $=100$ $\mu \mathrm{m} .{ }^{\mathrm{a}} p<0.05$, compared with control group, ${ }^{\mathrm{b}} p<0.05$, compared with $25 \%$ FBS group. FBS, fetal bovine serum; NCTD, norcantharidin. 
Kidney

Blood Pressure

Research

\begin{tabular}{l|l}
\hline Kidney Blood Press Res 2019;44:1339-1351 \\
\hline DOI: 10.1159/000502524 & $\begin{array}{l}\text { @ 2019 The Author(s). Published by S. Karger AG, Basel } \\
\text { www.karger.com/kbr }\end{array}$ \\
\hline
\end{tabular}

Ye et al.: NCTD Enhances High Concentrations of FBS-Induced Apoptosis in HMCs by Regulating the MAPK Signaling Pathway

A

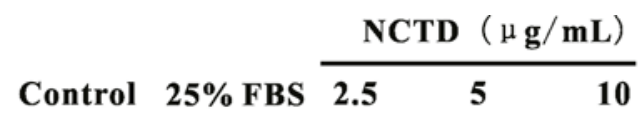

p-Erk1/2

Erk1/2
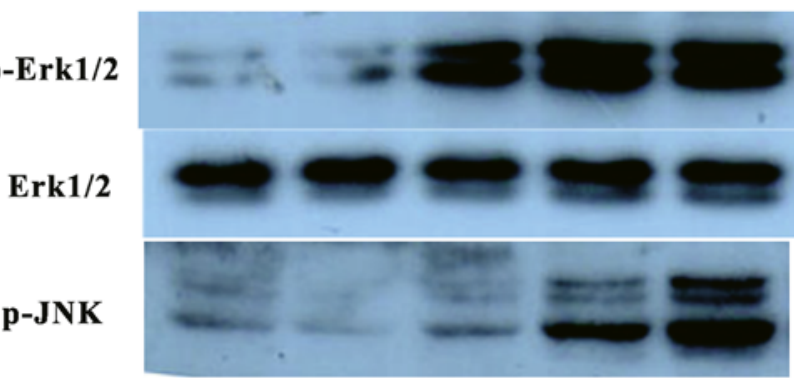

p-JNK

JNK

p-p38

p38

p53

GAPDH
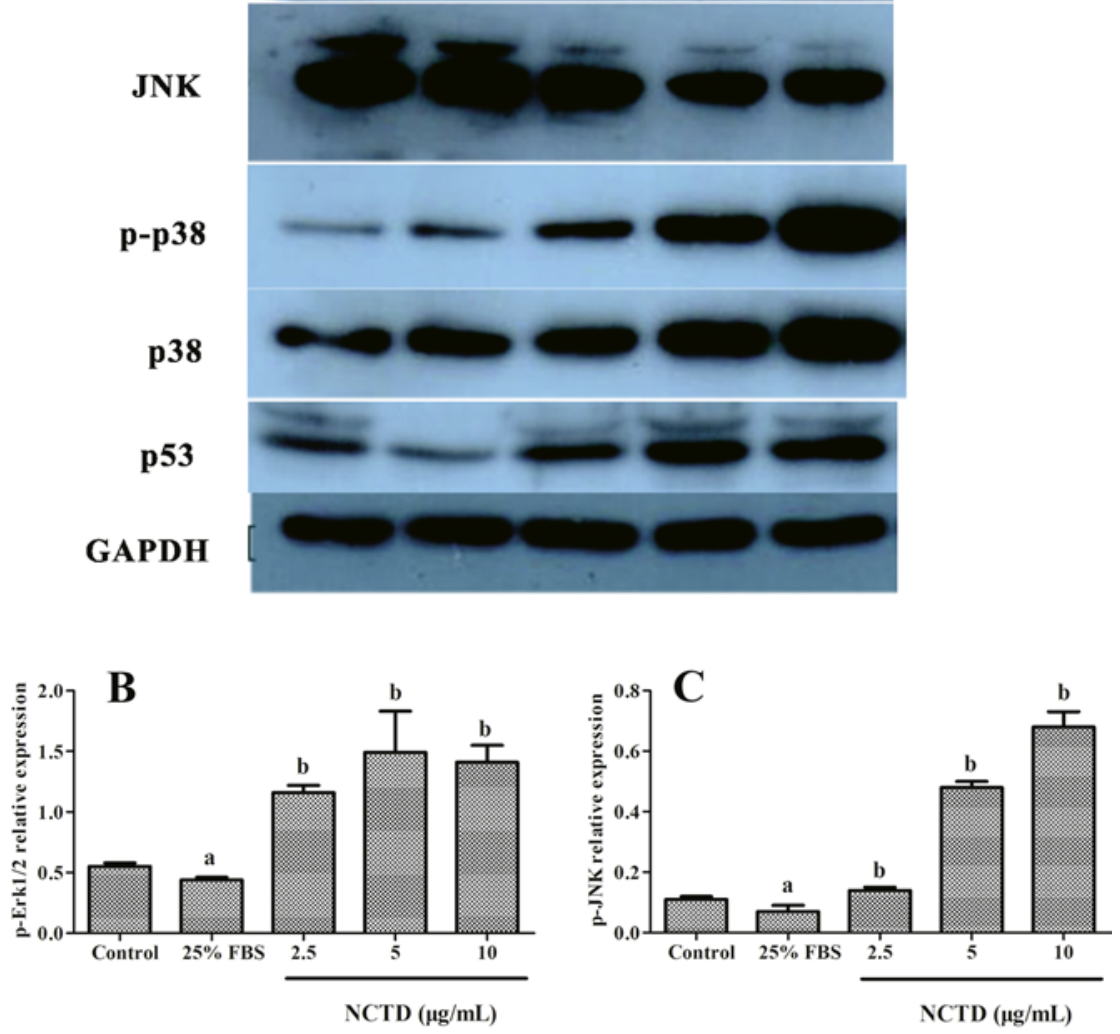

D

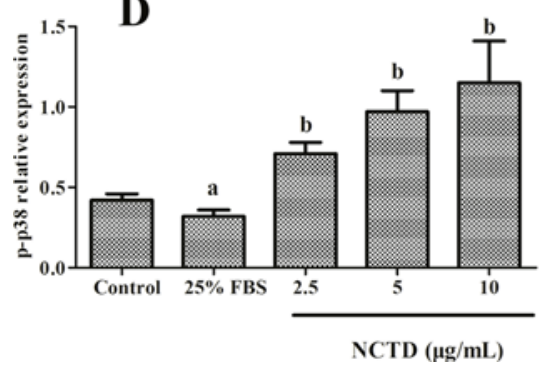

$\mathbf{E}$

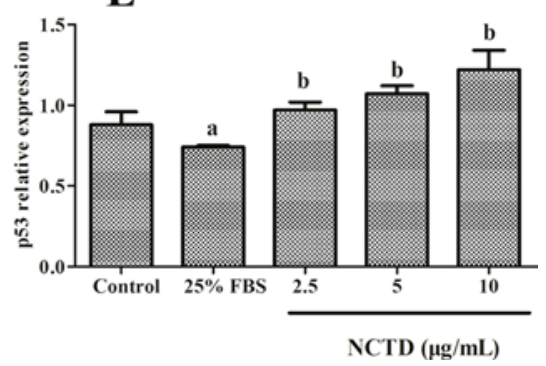

Fig. 5. Effect of NCTD on apoptotic-related protein expression. The bands are from a representative blot. Values are presented as the mean $\pm \operatorname{SD}(n=3)$. ${ }^{\mathrm{a}} p<0.05$, compared with control group, ${ }^{\mathrm{b}} p<0.05$, compared with 25\% FBS group. p-JNK, Jun N-terminal kinase; FBS, fetal bovine serum; NCTD, norcantharidin. 


\section{Kidney \\ Blood Pressure \\ Research}

Fig. 6. Effect of NCTD on p53 mRNA expression. Values are presented as the mean $\pm \operatorname{SD}(n=3)$. a $p<0.05$, compared with control group, ${ }^{\mathrm{b}} p<0.05$, compared with $25 \%$ FBS group. FBS, fetal bovine serum; NCTD, norcantharidin.

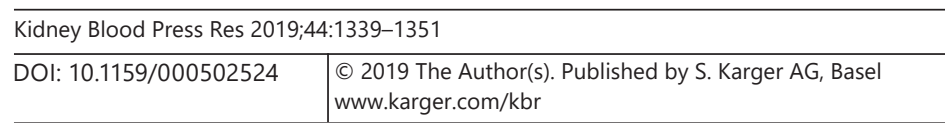

Ye et al.: NCTD Enhances High Concentrations of FBS-Induced Apoptosis in HMCs by Regulating the MAPK Signaling Pathway

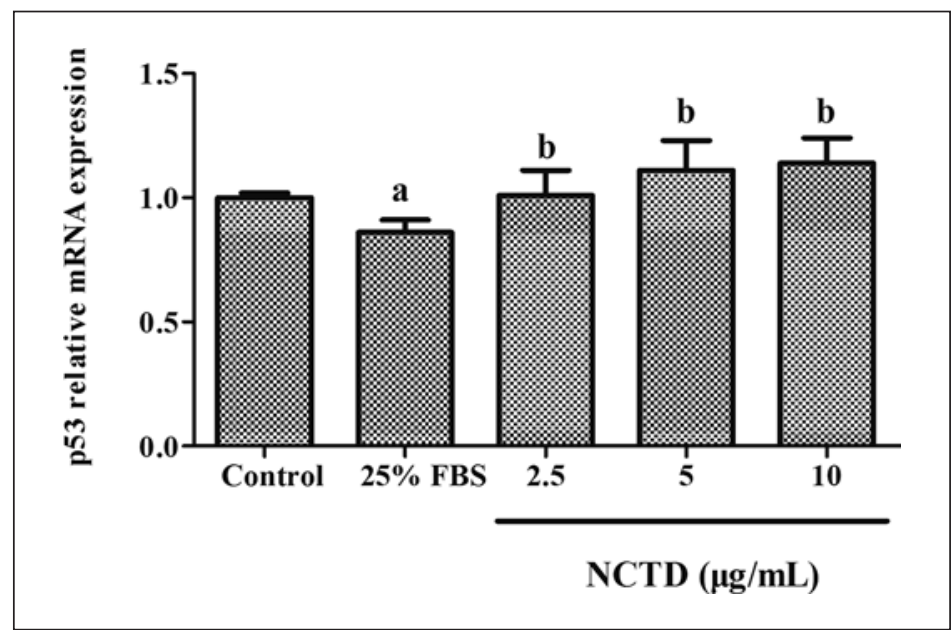

\section{Discussion}

HMC proliferation is the common feature of glomerulosclerosis, which can be induced by high concentration of FBS $[35,36]$. The previous study demonstrated that the growth of HMCs could be significantly inhibited by NCTD [29], and this may be mediated by inducing cell apoptosis and modulating the cell cycle. In the present study, a successful HMC proliferation model was established by incubating with $25 \%$ FBS, which was consistent with previous reports [35, 37]. The present results revealed that the administration of NCTD inhibited HMC proliferation in a concentration-dependent manner. Moreover, NCTD improved HMC apoptosis, which was evidenced by the decrease in $\Delta \psi \mathrm{m}$, the increase in apoptosis rate, the release of cytochrome c, and the apoptotic-related gene/protein expression. Importantly, the underlying mechanism of NCTD proapoptosis may involve the regulation of MAPK signaling pathway. These results suggested that the NCTD had the potential to attenuate MsPGN.

Apoptosis and programmed cell death are crucial mechanisms of proliferation inhibition [15]. The present study demonstrated that NCTD reduced cell viability and increased apoptosis in HMCs treated with 25\% FBS. In addition to nuclear condensation, the number of apoptotic cells increased after NCTD treatment, which was confirmed by Hoechst 33258 staining and higher blue florescence occurrence.

Apoptosis can be induced by the intrinsic or extrinsic pathway. It was found that NCTDinduced cell apoptosis was accompanied with cytochrome c release, which is the hallmark of apoptosis induction through the intrinsic pathway [38, 39]. Moreover, it was also found that NCTD regulated the expression of the bcl-2 family, which is mainly involved in the intrinsic pathway of apoptosis. In addition, NCTD enhanced the extrinsic pathway factor caspase-3, which improves cell apoptosis.

Mitochondria, as the major energy generator in cells, play a vital role in cell apoptosis induced by stimuli. It has been reported that agents decreased the levels of $\Delta \psi \mathrm{m}$, which may lead to apoptosis in cells through the mitochondria-dependent pathway [40]. Thus, $\Delta \psi \mathrm{m}$ is further characterized, as indicated by the decrease in JC-1 dye. It is well-known that JC-1 red fluorescence in normal cells and the reduction of mitochondrial membrane potential leads to the replacement of red fluorescence by green JC-1 monomers, and the decreasing of ratio of $\mathrm{red} /$ green fluorescence indicates the loss of $\Delta \psi \mathrm{m}$ [41]. The present study revealed that mitochondrial depolarization became remarkable with NCTD treatments, as evidenced by NCTD, which caused decrease in JC- 1 aggregates and dose-dependent increase in JC-1 monomers. The present study was in agreement with another study, in which NCTD-induced cytotoxicity 


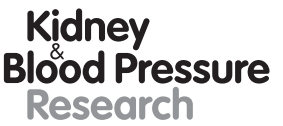

Research \begin{tabular}{l|l}
\hline Kidney Blood Press Res 2019;44:1339-1351 \\
\hline DOI: 10.1159/000502524 & $\begin{array}{l}\text { @ 2019 The Author(s). Published by S. Karger AG, Basel } \\
\text { www.karger.com/kbr }\end{array}$ \\
\hline Ye et al.: NCTD Enhances High Concentrations of FBS-Induced Apoptosis in HMCs by
\end{tabular}

Regulating the MAPK Signaling Pathway

in tumor cells by apoptosis, and this was probably mediated through the mitochondrialdependent pathway [18]. The present results suggested that the reason why NCTD could induce apoptosis of HMCs was that the induced release of cytochrome $\mathrm{c}$ into the cytoplasm disrupted the mitochondrial permeability.

In the present study, it was observed that NCTD increased the level of caspase-3, but inhibited that of MMP2 and MMP9. In order to further explore the mechanism underlying the NCTD-induced apoptosis, the MAPK signaling pathway was investigated. As a member of the MAPK family, JNK is mainly responsible for apoptosis induction. The activated p-p38 contributes to the induction of apoptosis and inhibition of cell proliferation [42, 43]. P53 is involved in coordinating apoptosis to preserve genomic stability and prevent cell excessive proliferation $[11,44]$. Blocking the phosphorylation of MAPK generates the subsequent inhibition of apoptosis through the regulation of caspase-3 activity [45]. The present study demonstrated that NCTD induced the phosphorylation of JNK and p38 and increased the expression of p53, which suggested the involvement of the activation of JNK and p38, and the expression of $\mathrm{p} 53$ in the antiproliferation effects of NCTD.

The classical ERK family (p42/44 MAPK) is known to be an intracellular checkpoint for controlling cellular $\mathrm{G}_{0} / \mathrm{G}_{1}$ mitogenic signals and cell cycle progression $[46,47]$. Traditionally, growth factors and several cytokine receptors activate the ERK pathway by the JAK cascade, eventually leading to cell proliferation, differentiation, and development [48]. Although the survival rate can be promoted by the activation and phosphorylation of Erk1/2 [49], contradictory evidence has revealed that the activation of Erk1/2 drives cells to death [50]. The present results supported the latter opinion and revealed that NCTD increased phosphorylation and induced apoptosis. However, the underlying mechanism remains to be determined through further studies.

Several limitations still exist in the present study. First, the sample size was relatively small. In addition, the up- and downstream signal factors in the ERK pathway were not measured in the present study, and animal models are needed to further evaluate the effect of NCTD on the inhibition of cell proliferation.

In conclusion, the present finding demonstrates for the first time that the administration of NCTD induces $25 \%$ FBS-treated HMC apoptosis. This effect may be mediated by the ERK, JNK, and p38 MAPK signaling pathways. The present findings suggest that NCTD may be a potential antiproliferation drug for the MsPGN. However, further studies in vivo are required to confirm these findings.

\section{Acknowledgments}

This work was supported by the National Natural Science Foundation of China (81260121). We thank all members of the Research Center of Medical Sciences (The People's Hospital of Guangxi Zhuang Autonomous Region, 6 Taoyuan Road, Nanning 530021, China) for support and discussions.

\section{Disclosure Statement}

The authors declare that there are no conflicts of interest. 


\begin{tabular}{l|l}
\hline Kidney Blood Press Res 2019;44:1339-1351 \\
\hline DOI: 10.1159/000502524 & $\begin{array}{l}\text { ○ 2019 The Author(s). Published by S. Karger AG, Basel } \\
\text { www.karger.com/kbr }\end{array}$ \\
\hline
\end{tabular}

Ye et al.: NCTD Enhances High Concentrations of FBS-Induced Apoptosis in HMCs by Regulating the MAPK Signaling Pathway

\section{References}

1 Radhakrishnan J, Cattran DC. The KDIGO practice guideline on glomerulonephritis: reading between the (guide)lines-application to the individual patient. Kidney Int. 2012 Oct;82(8):840-56.

2 Beck L, Bomback AS, Choi MJ, Holzman LB, Langford C, Mariani LH, et al. KDOQI US commentary on the 2012 KDIGO clinical practice guideline for glomerulonephritis. Am J Kidney Dis. 2013 Sep;62(3):403-41.

3 Barbour S, Beaulieu M, Gill J, Espino-Hernandez G, Reich HN, Levin A. The need for improved uptake of the KDIGO glomerulonephritis guidelines into clinical practice in Canada: a survey of nephrologists. Clin Kidney J. 2014 Dec; 7(6):538-45.

4 Floege J, Amann K. Primary glomerulonephritides. Lancet. 2016 May;387(10032):2036-48.

5 Chen D, Li Y, Mei Y, Geng W, Yang J, Hong Q, et al. miR-34a regulates mesangial cell proliferation via the PDGFR- $\beta$ /Ras-MAPK signaling pathway. Cell Mol Life Sci. 2014 Oct;71(20):4027-42.

6 Mao S, Jiang T, Shang G, Wu Z, Zhang N. Increased expression of neutrophil gelatinase-associated lipocalin receptor by interleukin-1 $\beta$ in human mesangial cells via MAPK/ERK activation. Int J Mol Med. 2011 Apr;27(4): 555-60.

7 Sandau KB, Callsen D, Brüne B. Protection against nitric oxide-induced apoptosis in rat mesangial cells demands mitogen-activated protein kinases and reduced glutathione. Mol Pharmacol. 1999 Oct;56(4):74451.

8 Cao F, Liu T, Xu Y, Xu D, Feng S. Curcumin inhibits cell proliferation and promotes apoptosis in human osteoclastoma cell through MMP-9, NF- $\kappa B$ and JNK signaling pathways. Int J Clin Exp Pathol. 2015 Jun;8(6):603745.

9 Zhang C, Chen Y, Gan X, Huang Z, Zou M, Fu W, et al. SAK-HV Decreases the Self-Ubiquitination of MEKK1 to Promote Macrophage Proliferation via MAPK/ERK and JNK Pathways. Int J Mol Sci. 2017 Apr;18(4):e835.

10 Moriwaki K, Asahi M. Augmented TME 0-GlcNAcylation Promotes Tumor Proliferation through the Inhibition of p38 MAPK. Mol Cancer Res. 2017 Sep;15(9):1287-98.

11 Leber B, Geng F, Kale J, Andrews DW. Drugs targeting Bcl-2 family members as an emerging strategy in cancer. Expert Rev Mol Med. 2010 Sep;12(9):e28.

12 Yang L, Shu T, Liang Y, Gu W, Wang C, Song X, et al. GDC-0152 attenuates the malignant progression of osteosarcoma promoted by ANGPTL2 via PI3K/AKT but not p38MAPK signaling pathway. Int J Oncol. 2015 Apr; 46(4):1651-8.

13 Chang L, Karin M. Mammalian MAP kinase signalling cascades. Nature. 2001 Mar;410(6824):37-40.

14 Boutros T, Chevet E, Metrakos P. Mitogen-activated protein (MAP) kinase/MAP kinase phosphatase regulation: roles in cell growth, death, and cancer. Pharmacol Rev. 2008 Sep;60(3):261-310.

15 Pal D, Sharma U, Singh SK, Kakkar N, Prasad R. Over-expression of telomere binding factors (TRF1 \& TRF2) in renal cell carcinoma and their inhibition by using SiRNA induce apoptosis, reduce cell proliferation and migration invitro. PLoS One. 2015 Mar;10(3):e0115651.

16 Chen AW, Tseng YS, Lin CC, Hsi YT, Lo YS, Chuang YC, et al. Norcantharidin induce apoptosis in human nasopharyngeal carcinoma through caspase and mitochondrial pathway. Environ Toxicol. 2018 Mar;33(3):34350.

17 Jiang Z, Chi J, Han B, Liu W. Preparation and pharmacological evaluation of norcantharidin-conjugated carboxymethyl chitosan in mice bearing hepatocellular carcinoma. Carbohydr Polym. 2017 Oct;174:282-90.

18 Zheng LC, Yang MD, Kuo CL, Lin CH, Fan MJ, Chou YC, et al. Norcantharidin-induced Apoptosis of AGS Human Gastric Cancer Cells Through Reactive Oxygen Species Production, and Caspase- and Mitochondria-dependent Signaling Pathways. Anticancer Res. 2016 Nov;36(11):6031-42.

19 Wu MH, Chiou HL, Lin CL, Lin CY, Yang SF, Hsieh YH. Induction of endoplasmic reticulum stress and mitochondrial dysfunction dependent apoptosis signaling pathway in human renal cancer cells by norcantharidin. Oncotarget. 2017 Dec;9(4):4787-97.

20 Peng C, Li Z, Niu Z, Niu W, Xu Z, Gao H, et al. Norcantharidin Suppresses Colon Cancer Cell Epithelial-Mesenchymal Transition by Inhibiting the $\alpha v \beta 6$-ERK-Ets1 Signaling Pathway. Sci Rep. 2016 Feb;6(1):20500.

21 Yang PY, Hu DN, Kao YH, Lin IC, Chou CY, Wu YC. Norcantharidin induces apoptosis in human prostate cancer cells through both intrinsic and extrinsic pathways. Pharmacol Rep. 2016 Oct;68(5):874-80.

22 Yeh CB, Hsieh MJ, Hsieh YH, Chien MH, Chiou HL, Yang SF. Antimetastatic effects of norcantharidin on hepatocellular carcinoma by transcriptional inhibition of MMP-9 through modulation of NF-kB activity. PLoS One. 2012;7(2):e31055.

23 Hsieh FS, Hung MH, Wang CY, Chen YL, Hsiao YJ, Tsai MH, et al. Inhibition of protein phosphatase 5 suppresses non-small cell lung cancer through AMP-activated kinase activation. Lung Cancer. 2017 Oct;112:81-9.

24 Wang D, Yang C, Wang Z, Yang Y, Li D, Ding X, et al. Norcantharidin combined with Coix seed oil synergistically induces apoptosis and inhibits hepatocellular carcinoma growth by downregulating regulatory T cells accumulation. Sci Rep. 2017 Aug;7(1):9373.

25 Li Y, Ge Y, Liu FY, Peng YM, Sun L, Li J, et al. Norcantharidin, a protective therapeutic agent in renal tubulointerstitial fibrosis. Mol Cell Biochem. 2012 Feb;361(1-2):79-83.

26 Hou T, Xiao Z, Li Y, You YH, Li H, Liu YP, et al. Norcantharidin inhibits renal interstitial fibrosis by downregulating PP2Ac expression. Am J Transl Res. 2015 Nov;7(11):2199-211.

27 Liu FY, Li Y, Peng YM, Ye K, Li J, Liu YH, et al. Norcantharidin ameliorates proteinuria, associated tubulointerstitial inflammation and fibrosis in protein overload nephropathy. Am J Nephrol. 2008;28(3):465-77. 


\section{Kidney \\ Blood Pressure \\ Research}

\begin{tabular}{l|l}
\hline Kidney Blood Press Res 2019;44:1339-1351 \\
\hline DOI: 10.1159/000502524 & $\begin{array}{l}\text { @ 2019 The Author(s). Published by S. Karger AG, Basel } \\
\text { www.karger.com/kbr }\end{array}$ \\
\hline
\end{tabular}

Ye et al.: NCTD Enhances High Concentrations of FBS-Induced Apoptosis in HMCs by Regulating the MAPK Signaling Pathway

28 Chen YJ, Tsai YM, Kuo CD, Ku KL, Shie HS, Liao HF. Norcantharidin is a small-molecule synthetic compound with anti-angiogenesis effect. Life Sci. 2009 Oct;85(17-18):642-51.

29 Ye K, Wei Q, Gong Z, Huang Y, Liu H, Li Y, et al. Effect of norcantharidin on the proliferation, apoptosis, and cell cycle of human mesangial cells. Ren Fail. 2017 Nov;39(1):458-64.

30 Massicot F, Dutertre-Catella H, Pham-Huy C, Liu XH, Duc HT, Warnet JM. In vitro assessment of renal toxicity and inflammatory events of two protein phosphatase inhibitors cantharidin and nor-cantharidin. Basic Clin Pharmacol Toxicol. 2005 Jan; 96(1):26-32.

31 Xie Q, Zhang S, Chen C, Li J, Wei X, Xu X, et al. Protective Effect of 2-Dodecyl-6-Methoxycyclohexa-2, 5-Diene-1, 4-Dione, Isolated from Averrhoa Carambola L., Against Palmitic Acid-Induced Inflammation and Apoptosis in Min6 Cells by Inhibiting the TLR4-MyD88-NF-кB Signaling Pathway. Cell Physiol Biochem. 2016;39(5):170515.

32 García CP, Videla Richardson GA, Dimopoulos NA, Fernandez Espinosa DD, Miriuka SG, Sevlever GE, et al. Human Pluripotent Stem Cells and Derived Neuroprogenitors Display Differential Degrees of Susceptibility to BH3 Mimetics ABT-263, WEHI-539 and ABT-199. PLoS One. 2016 Mar;11(3):e0152607.

33 Doan VM, Chen C, Lin X, Nguyen VP, Nong Z, Li W, et al. Yulangsan polysaccharide improves redox homeostasis and immune impairment in D-galactose-induced mimetic aging. Food Funct. 2015 May;6(5):1712-8.

34 Chen C, Lu W, Wu G, Lv L, Chen W, Huang L, et al. Cardioprotective effects of combined therapy with diltiazem and superoxide dismutase on myocardial ischemia-reperfusion injury in rats. Life Sci. 2017 Aug;183:50-9.

35 Barnes JL, Woodruff KA, Levine SP, Abboud HE. Inhibition of mesangial cell proliferation by platelet factor 4. J Am Soc Nephrol. 1996 Jul;7(7):991-8.

36 Eto S, Isome M, Sano H, Fukuda Y, Kawasaki Y, Suzuki J, et al. Agmatine suppresses mesangial cell proliferation by modulating polyamine metabolism. Tohoku J Exp Med. 2006 Oct;210(2):145-51.

37 Lee BC, Doo HK, Lee HJ, Jin SY, Jung JH, Hong SJ, et al. The inhibitory effects of aqueous extract of Magnolia officinalis on human mesangial cell proliferation by regulation of platelet-derived growth factor-BB and transforming growth factor-beta1 expression. J Pharmacol Sci. 2004 Jan;94(1):81-5.

38 Tait SW, Green DR. Mitochondria and cell death: outer membrane permeabilization and beyond. Nat Rev Mol Cell Biol. 2010 Sep;11(9):621-32.

39 Kluck RM, Bossy-Wetzel E, Green DR, Newmeyer DD. The release of cytochrome c from mitochondria: a primary site for Bcl-2 regulation of apoptosis. Science. 1997 Feb;275(5303):1132-6.

40 Häcker G, Paschen SA. Therapeutic targets in the mitochondrial apoptotic pathway. Expert Opin Ther Targets. 2007 Apr;11(4):515-26.

41 Wang R, Deng D, Shao N, Xu Y, Xue L, Peng Y, et al. Evodiamine activates cellular apoptosis through suppressing PI3K/AKT and activating MAPK in glioma. OncoTargets Ther. 2018 Mar;11:1183-92.

42 Uchakina ON, Ban H, McKallip RJ. Targeting hyaluronic acid production for the treatment of leukemia: treatment with 4-methylumbelliferone leads to induction of MAPK-mediated apoptosis in K562 leukemia. Leuk Res. 2013 Oct;37(10):1294-301.

43 Kim SW, Lim CM, Kim JB, Shin JH, Lee S, Lee M, et al. Extracellular HMGB1 released by NMDA treatment confers neuronal apoptosis via RAGE-p38 MAPK/ERK signaling pathway. Neurotox Res. 2011 Aug;20(2):159-69.

44 An HK, Kim KS, Lee JW, Park MH, Moon HI, Park SJ, et al. Mimulone-induced autophagy through p53-mediated AMPK/mTOR pathway increases caspase-mediated apoptotic cell death in A549 human lung cancer cells. PLoS One. 2014 Dec;9(12):e114607.

45 Li WW, Gao XM, Wang XM, Guo H, Zhang BL. Icariin inhibits hydrogen peroxide-induced toxicity through inhibition of phosphorylation of JNK/p38 MAPK and p53 activity. Mutat Res. 2011 Mar;708(1-2):1-10.

46 Tamemoto H, Kadowaki T, Tobe K, Ueki K, Izumi T, Chatani Y, et al. Biphasic activation of two mitogen-activated protein kinases during the cell cycle in mammalian cells. J Biol Chem. 1992 Oct;267(28):20293-7.

47 Buchkovich KJ, Ziff EB. Nerve growth factor regulates the expression and activity of p33cdk2 and p34cdc2 kinases in PC12 pheochromocytoma cells. Mol Biol Cell. 1994 Nov;5(11):1225-41.

48 Zhang W, Liu HT. MAPK signal pathways in the regulation of cell proliferation in mammalian cells. Cell Res. 2002 Mar;12(1):9-18.

49 Rahiman N, Akaberi M, Sahebkar A, Emami SA, Tayarani-Najaran Z. Protective effects of saffron and its active components against oxidative stress and apoptosis in endothelial cells. Microvasc Res. 2018 Jul;118:82-9.

50 Dohi K, Mizushima H, Nakajo S, Ohtaki H, Matsunaga S, Aruga T, et al. Pituitary adenylate cyclase-activating polypeptide (PACAP) prevents hippocampal neurons from apoptosis by inhibiting JNK/SAPK and p38 signal transduction pathways. Regul Pept. 2002 Nov;109(1-3):83-8. 